\title{
Association of Vitamin B12 Deficiency with Long term Metformin use for more than 4 years and greater than 1000 Milligrams in Type 2 Diabetes Mellitus
}

Authors

\section{Dr Dheeravath Kalyani*, Dr Sudheer M.D}

*Corresponding Author

Dr Dheeravath Kalyani

Post Graduate, Department of General Medicine, Gems \& Hospital, Srikakulam, Andhra Pradesh, India

\section{Introduction}

Metformin is the most frequently prescribed medication in the management of Type 2 Diabetes Mellitus.

Metformin belongs to the biguanide class of oral antidiabetic drugs. The main site of metformin action is thought to be in the liver where the drug suppresses glucose production.

It promotes glucose uptake by tissues via the glucose transporters, and inhibits hepatic gluconeogenesis.

A range of additional affects such as improvements in endothelial function, hemostasis and oxidative stress, insulin resistance, lipid profiles, and fat redistribution accompany the primary glycemic function of metformin.

Metformin causes an impairment of calciumdependent membrane activity in the ileum which leads to malabsorption of Vitamin B12 bound to intrinsic factor leading to vitamin B12 deficiency. Diabetes mellitus (DM) refers to a group of common metabolic disorders that share the phenotype of hyperglycemia.
Several distinct types of DM are caused by a complex interaction of genetics and environmental factors.

Depending on the etiology of the DM, factors contributing to hyperglycemia include reduced insulin secretion, decreased glucose utilization, and increased glucose production.

The metabolic dysregulation associated with DM causes secondary pathophysiologic changes in multiple organ systems that impose a tremendous burden on the individual with diabetes and on the health care system.

Vitamin B12, also referred to as cobalamin $(\mathrm{Cbl})$, is thought to play a large role in the formation of red blood cells as well as key roles in brain and nerve function.

Vitamin B12 deficiency presents as neuropathy of the feet and development of anemia.

Neuropathy as a result of Vitamin B12 deficiency is particularly difficult to identify as it mimics that of diabetic neuropathy and can take a long period of time to develop. 


\section{Aim of the Study}

This study was undertaken to evaluate the association of vitamin B12 deficiency with long term metformin therapy.

\section{Material and Methods}

Study Design: A prospective, descriptive study.

Study site and Population: Patients with type 2 diabetes mellitus using metformin longer than 4years and greater than $1000 \mathrm{mg}$ admitted to Great Eastern Medical School and Hospital, fulfilling the inclusion and exclusion criteria.

Study Period: After obtaining approval of Ethical Committee, study was conducted for a period of 12 months from June 2020 to May 2021.

\section{Inclusion Criteria}

1) Patients with fasting blood glucose $>126$ $\mathrm{mg} / \mathrm{dl}$ on two different occasions, post prandial blood glucose > $200 \mathrm{mg} / \mathrm{dl}$. $\mathrm{HbA} 1 \mathrm{C}>6.5 \%$, OGTT $>200 \mathrm{mg} / \mathrm{dl}$.

2) Type 2 Diabetic patients of age $>18$ years and less than 65 years.

3) Type 2 Diabetic patients on intake of metformin greater than $1000 \mathrm{mg}$ and longer than 4yrs

\section{Exclusion Criteria}

1) Type 1 diabetes mellitus

2) Intake of calcium

3) Malabsorption Syndrome

4) Intestinal infection

5) Partial/total gastrectomy

6) Patients on vitamin B12 supplements

7) Hypothyroidism

8) Strict vegetarians

9) Patients on antiepileptics

\section{Sample Size: 70}

\section{Data Collection Tools}

Data was collected using a pretested proforma meeting the objectives of the study. Those patients who gave written consent for the study and fulfilled the inclusion and exclusion criteria were included. Detailed history, necessary investigations have been undertaken. The analysis of data was done by using $p$ value and chi square test. Ethical committee approval has been taken for the study.

\section{Vitamin B12 and Folate}

Vitamin B-12 and folate concentrations were determined by an electrochemiluminescence immunoassay (ECLIA). Serum vitamin $B_{12}$ tests results are in $\mathrm{pg} / \mathrm{mL}$ (picograms /milliliter). Vitamin B12 levels in humans is considered as normal if $>300 \mathrm{pg} / \mathrm{mL}$, deficiency defined as vitamin b12 levels $\leq 300 \mathrm{pg} / \mathrm{mL}^{112}$

\section{Investigations}

1) Fasting blood glucose, 2) Post prandial blood glucose, 3) HbA1C, 4) Serum vitamin B12 levels, folate levels, 5) Complete blood picture with peripheral smear

\section{Statistical Analysis}

- All the data was entered in Microsoft excel sheet, and then analyzed with appropriate statistical tools. The data was analyzed statistically by using statistical software SPSS version 0.85. Data was presented as mean with standard deviation or proportions as appropriate. Mean, median, standard deviation and variance was calculated and following statistical significance tests were applied.

- Appropriate statistical test was applied qualitatively by Chi-square and quantitatively by Z- test. Student's paired T-test was used as the statistical tool to test for significance of observed mean differences. A p value $<0.05$ is considered significant 


\section{Observation and Results}

Age Distribution in study population:

Maximum number of patients with diabetes was observed in age group between 51 to 60 years, accounting for $25(35.7 \%)$ patients.

\begin{tabular}{|l|c|c|}
\hline Age group & No. of patients & \% \\
\hline$<\mathbf{3 0}$ & 1 & $1.4 \%$ \\
\hline $\mathbf{3 1 - 4 0}$ & 9 & $12.8 \%$ \\
\hline $\mathbf{4 1 - 5 0}$ & 20 & $28.6 \%$ \\
\hline $\mathbf{5 1 - 6 0}$ & 25 & $35.7 \%$ \\
\hline$>\mathbf{6 0}$ & 15 & $21.4 \%$ \\
\hline Total & 70 & $100.0 \%$ \\
\hline \multicolumn{2}{|c|}{ Mean Age: 52.17 (29-64 years) } & \\
\hline
\end{tabular}

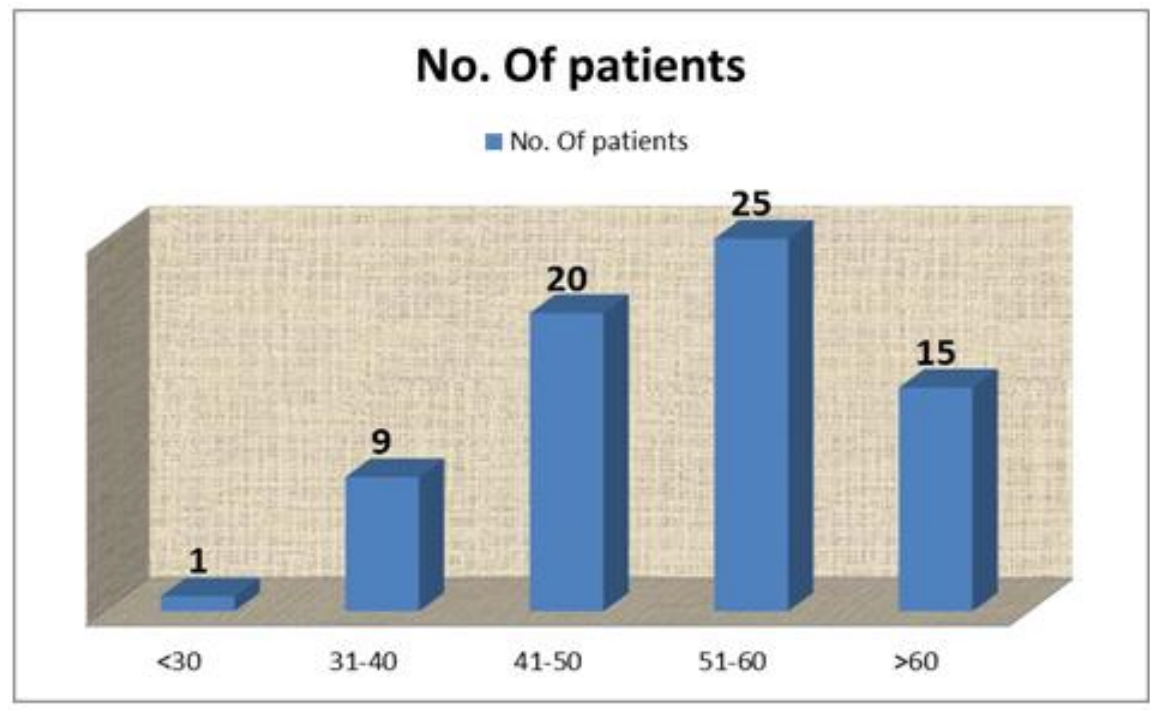

\section{Sex Distribution in study population}

In this study of 70 patients we observed, 30(42.9\%) patients were males and 40(57.1\%) female patients.

Sex Distribution of study population

\begin{tabular}{|l|c|c|}
\hline Sex & No. of patients & \% \\
\hline Female & 40 & $57.1 \%$ \\
\hline Male & 30 & $42.9 \%$ \\
\hline Total & 70 & $100.0 \%$ \\
\hline
\end{tabular}

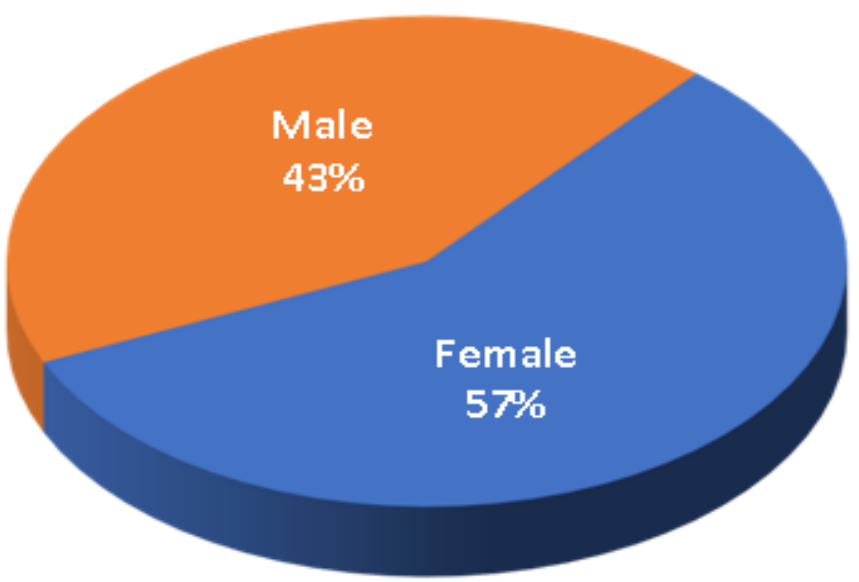




\section{Duration of diabetes in study population}

No. of patients

In the present study population mean duration of diabetes in subjects was 8.45 yrs. Maximum number (39) of patients having diabetes for $>10$ years. Only 4 patients were having duration of diabetes less than 5 years.

\begin{tabular}{|l|c|c|}
\hline Duration of DM & No. of Patients & \% \\
\hline$<\mathbf{5}$ yrs & 4 & $5.7 \%$ \\
\hline $\mathbf{5 - 1 0}$ yrs & 27 & $38.6 \%$ \\
\hline$>\mathbf{1 0}$ yrs. & 39 & $55.7 \%$ \\
\hline Total & 70 & $100.0 \%$ \\
\hline Mean duration: 11.77 yrs & & \\
\hline
\end{tabular}

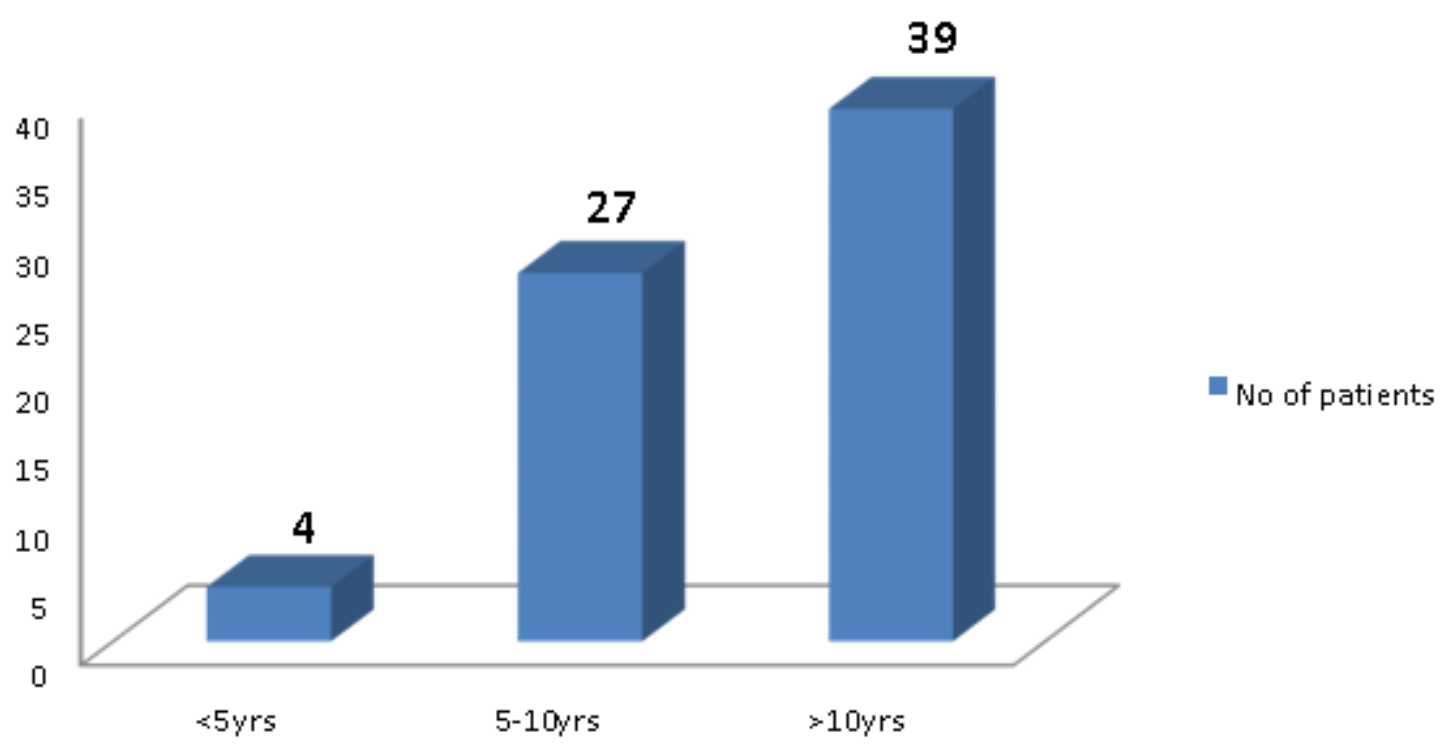

\section{Duration of metformin therapy in study population:}

- In our study population 55 (78.6\%) patients were taking metformin for 4 to $10 \mathrm{yrs}$.

- $15(21.4 \%)$ patients were using metformin for more than $10 \mathrm{yrs}$.

\section{Duration of metformin therapy}

\begin{tabular}{|l|c|c|}
\hline Duration of Metformin & No. of patients & \% \\
\hline 4-10 years & 55 & $78.6 \%$ \\
\hline > 10 years & 15 & $21.4 \%$ \\
\hline Total & 70 & $100.0 \%$ \\
\hline
\end{tabular}

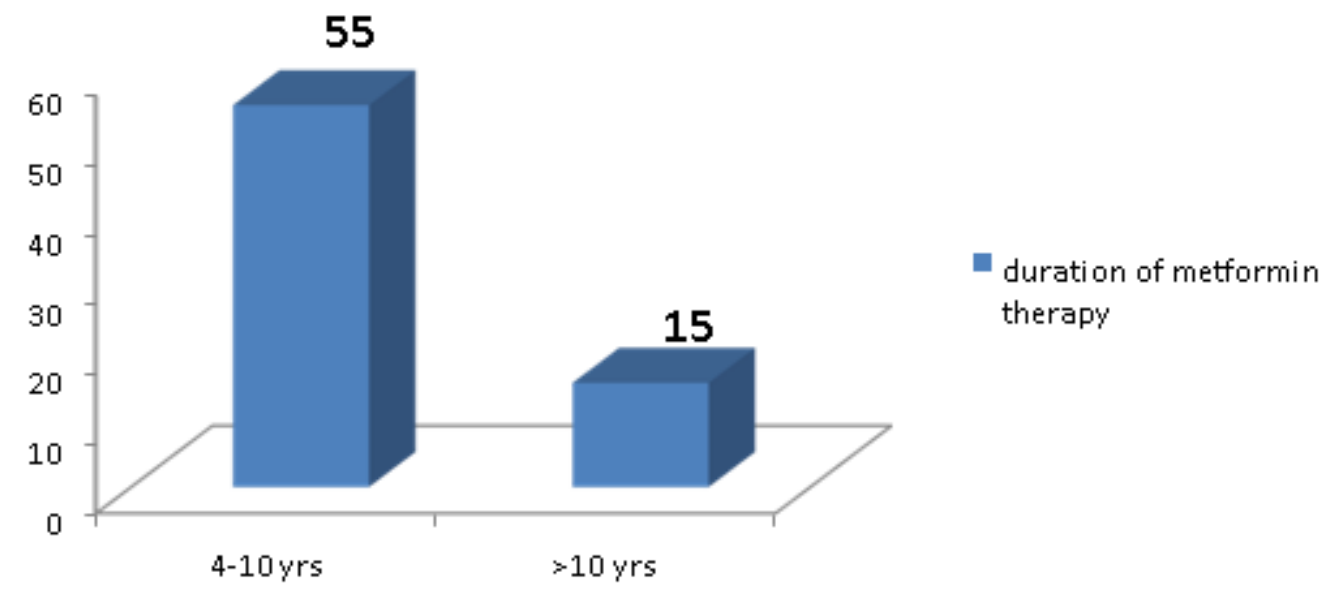


Mean laboratory values of study population

In the present diabetic population mean fasting and postprandial blood sugar levels were $176.9 \mathrm{mg} / \mathrm{dl}, 282.6 \mathrm{mg} / \mathrm{dl}$ respectively. Mean HbA1c level was 6.93. Mean serum vitamin B12 and folate levels were $603.9 \mathrm{pg} / \mathrm{ml}, 10.3 \mathrm{ng} / \mathrm{ml}$ respectively. Mean hemoglobin level in study population was $11.85 \mathrm{gm} / \mathrm{dl}$.

\section{Vitamin B12 status in study population}

In the present study population out of 70 patients 10 patients having vitamin B12 deficiency, in those 10 people 6 people were female, 4 people were male. 60 patients had normal serum vitamin B12 levels

\section{Vitamin B12 Deficiency}

\begin{tabular}{|l|c|c|}
\hline Vitamin B 12 Deficiency & No. of patients & \% \\
\hline Yes $(\leq \mathbf{3 0 0} \mathbf{~ p g} / \mathbf{m L})$ & 10 & $14.3 \%$ \\
\hline No $(>\mathbf{3 0 0} \mathbf{~ g g} / \mathbf{m L})$ & 60 & $85.7 \%$ \\
\hline Total & 70 & $100.0 \%$ \\
\hline
\end{tabular}

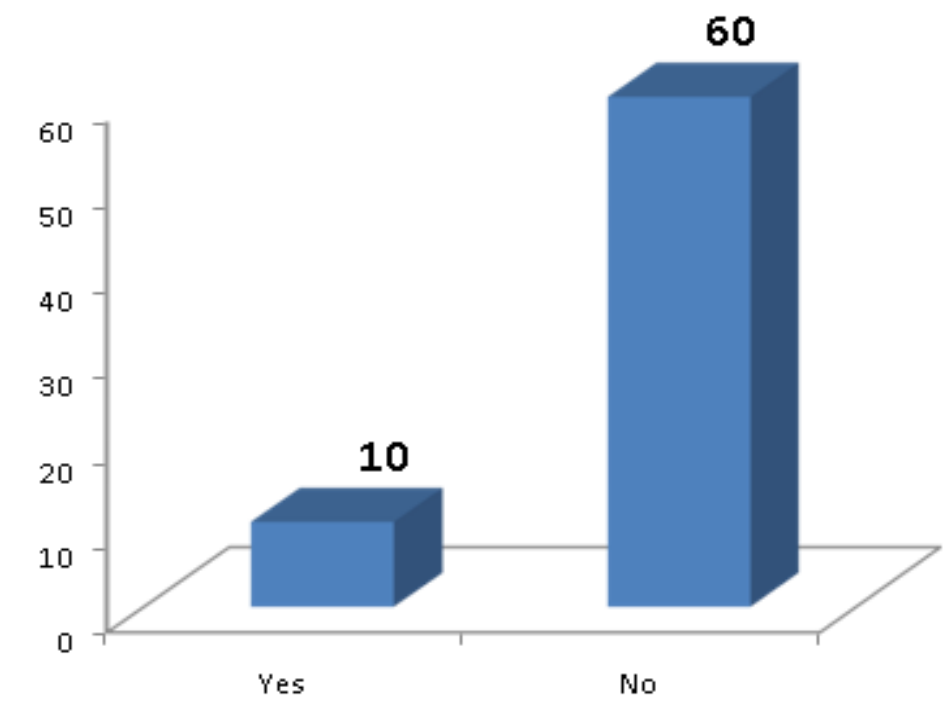

\begin{tabular}{|l|c|}
\hline Parameter & Mean \\
\hline FPG (mg\%) & 176.9 \\
\hline PPG (mg\%) & 282.6 \\
\hline HbA1C (\%) & 6.93 \\
\hline Vitamin B12 Levels (pg/ml) & 603.9 \\
\hline Folate levels (ng/ml) & 10.3 \\
\hline Hemoglobin levels (gm\%) & 11.85 \\
\hline
\end{tabular}

Comparison of duration of metformin use and serum vitamin B12 status in the study population

\begin{tabular}{|c|c|c|c|}
\hline Duration of Metformin Use & \multicolumn{2}{|c|}{ Vitamin B 12 Deficiency } & \multirow{2}{*}{ Total } \\
\cline { 2 - 4 } & & & \\
\hline \multirow{2}{*}{ 4-10 years } & No (n-60) & Yes (n-10) & \\
& 52 & 3 & 55 \\
\cline { 2 - 4 } & $86.7 \%$ & $30.0 \%$ & $78.6 \%$ \\
\hline > 10 years & 8 & 7 & 15 \\
\cline { 2 - 4 } & $13.3 \%$ & $70.0 \%$ & $21.4 \%$ \\
\hline Total & 60 & 10 & 70 \\
\cline { 2 - 4 } & $100.0 \%$ & $100.0 \%$ & $100.0 \%$ \\
\hline p- value 0.005 & \multicolumn{3}{|c}{} \\
\hline
\end{tabular}




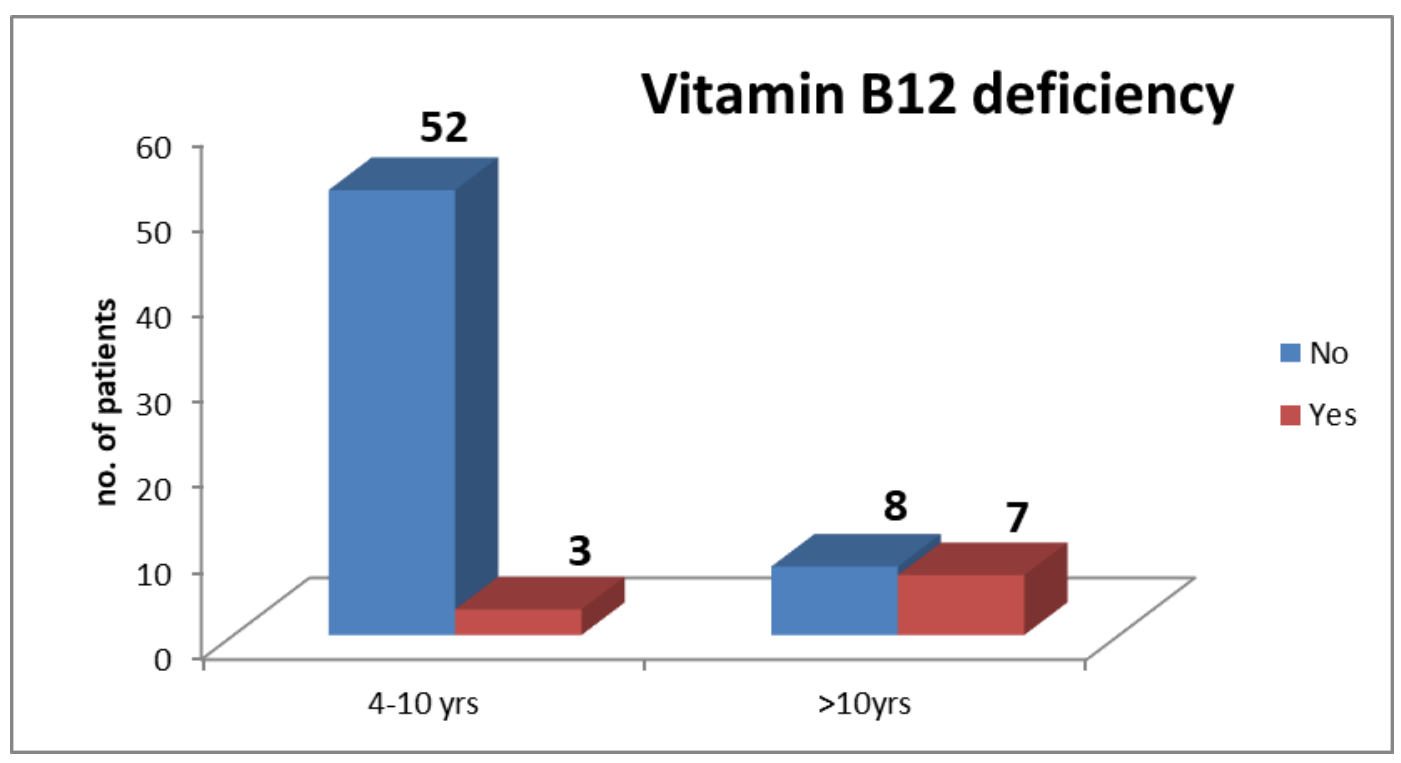

\section{Summary}

- The present study was a descriptive study, conducted at Great Eastern Medical School and Hospital.

- This study included patients with type 2 diabetes mellitus taking metformin for longer than 4 years and more than 1000mg admitted to our hospital. The study was conducted for 12 months from June 2020 to May 2021.

- Total 70 subjects satisfying inclusion criteria and exclusion criteria were selected to participate in the study after taking informed consent.

- The maximum number of subjects were in the age group of 51-60 years (52.9\%).

- Mean age in the present study was 52 years.

- Males comprised $42.9 \%$ of the study group while females comprised $57.1 \%$.

- No significant statistical relation was seen between levels of vitamin B12 levels and age, sex, hypertension, smoking status, alcohol status, HBA1C level ( $\mathrm{p}$ value $>0.05$ ).

- In our study, 20 patients out of 70 were anemic. $25 \%$ of subjects with vitamin B12 sufficient patients were anemic, where as $50 \%$ of B12 deficient patients were anemic. No statistical significance was present ( $p>0.05)$.

- In our study, It was observed that out of 70 subjects using metformin10 patients (14.3\%) have vitamin B12 deficiency which was found to be very highly significant ( $\mathrm{p}$ value $<0.05$ ).

- In our study, it was observed that $70 \%$ of vitamin B12 deficient patients were using metformin for more than 10yrs which is highly significant ( $\mathrm{p}$ value $<0.05$ ). So increase in duration of metformin use increases the risk of vitamin B12 deficiency.

- In our study, patients with vitamin B12 deficiency had mean duration of diabetes 12 years and without B12 deficiency had mean duration of diabetes of 11years which was non significant $(\mathrm{p}$ value $>0.05$ ).

- This study reveals strong positive significant association between vitamin B12 deficiency with long-term metformin use.

\section{Conclusions}

- In this study, the goal was to study the association of vitamin B12 deficiency with long term metformin use. The study was conducted at Great Eastern Medical 


\section{JMSCR VoI||09||Issue||12||Page 140-146||December}

School and Hospital, and included 70 patients using metformin for longer than 4 years and more than $1000 \mathrm{mg}$ satisfying inclusion and exclusion criteria. The following conclusions were drawn from our study:

1) In this study, there was highly significant association of vitamin B12 deficiency with longterm metformin use.

2) As duration of metformin use increases there is increased risk of vitamin B12 deficiency.

3) There was no significant association between vitamin B12 deficiency and duration of diabetes, HBA1C levels.

- On the basis of the present study findings, it can be concluded that vitamin B12 deficiency was strongly associated with long term metformin use.

\section{Recommendations}

1) Regular vitamin B12 monitoring in patients with type 2 diabetes has to be done particularly in patients receiving higher daily dosage of metformin treatment for a long time period.

2) Vitamin B12 supplementation should be done for patients using metformin for long period to prevent development of B12 deficiency

\section{References}

1. Bauman W, Shaw S, Jayatilleke E, Spungen A, Herbert V. Increased intake of calcium reverses vitamin B12 malabsorption induced by metformin. Diabetes Care. 2000;23:1227-31.

2. Mazokopakis EE, Starakis IK. Recommendations for diagnosis and management of metformin-induced vitamin B12 (Cbl) deficiency. Diabetes Res Clin Pract 2012;97:359-67.
3. Alvin C.Powers. Diabetes mellitus. In: Longo, Fauci, Kasper, Hauser, Jameson, Loscalzo. Harrison's Principles of Internal Medicine ,18th Edition. Newyork: Mc Graw Hill; 2012. p. 2968.

4. Bouchoucha M, Uzzan B, Cohen R. Metformin and digestive disorders. Diabetes Metab 2011;37:90-6.

5. Aroda V, Edelstein S, Goldberg R, Knowler W, Marcovina S, Orchard T et al. Long-term Metformin Use and Vitamin B12 Deficiency in the Diabetes Prevention Program Outcomes Study. The Journal of Clinical Endocrinology \& Metabolism. 2016;101:1754-61.

6. Haeusler S, Parry-Strong A, Krebs JD. The prevalence of low vitamin B12 status in people with type 2 diabetes receiving metformin therapy in $\mathrm{New}$ Zealand-a clinical audit. $\mathrm{N} Z \mathrm{Z}$ Med J. 2014;128:8-16. 